AT the annual meeting of the governors and supporters of the Devon and Exeter Hospital, held last week, the chief topic of interest appears to have been how best to meet the growing increase of expenditure over income. This seems to be so serious a feature in the affairs of the hospital that one gentleman said that if matters continued to go on as they had done the institution would be pauperised in twenty. five years' time. The only suggestion thrown out by way of remedy appears to have been the advisability of limiting the number of recommendations for hospital relief. Oltimately the meeting was adjourned till the 6th of June, with the understanding that a committee should then be appointed to devise means to balance receipts and expendi. ture.

WE understand that at St. Thomas's Hospital, on Wednesday, Mr. MacCormac removed the whole of the scapula with part of the clavicle of a woman, for a myxo-chondromatous growth weighing six pounds. The operation occupied twenty four minutes, and was attended with very slight hæmorrhage. The patient has since progressed un. interruptedly well. The wound has been daily treated antiseptically, and the whole surface dressed with salieysed cotton-wool under the personal supervision of $\mathrm{Mr}$. MacCormac. There has been very little traumatic fever.

WE are glad to learn that two new scholarships have recently been bequeathed to the Medical School of Guy's Hospital by former students. The late Mr. Sands Cox left a sum of $\$ 500$ invested so as to produce $\$ 15$ a year, the interest upon which is to be competed for once in three years. The other bequest was made by Mr. Michael Harris, M.B., lately deceased, the form of which is a prize in Anatomy of the value of $£ 10$, to be bestowed annually.

As we go to press, Mr. Errington will, in the House of Cummons, ask the Secretary of State for War whether it is not the case that in some thirty-five militia regiments the post of surgeon or assistant-surgeon, or both, are vacant owing to the appointments having been suspended for more than a year " pending new regulations," and if he will state, for the convenience of candidates waiting for appointment, how soon the vacancies are likely to be filled up.

THE deaths in London last week amounted to 1457 , giving an annual rate of mortality of 22 per thousand. The deaths included 1 from small-pox, 49 from measles, 31 from scarlet fever, 8 from diphtheria, 79 from whooping-cough, 25 from different forms of fever, 6 from diarrhcea, and 275 referred to diseases of the respiratory organs. Different kinds of violence caused 43 deaths. Latest returns from the other European capitals show that the continent is fairly healthy.

We presume that Dr. Ward was led to put the question he did to the Minister for War as to the employment of foreign surgeons for officering the Army and Navy Medical Departments, which was answered by Mr. Gathorne Hardy to the effect that the Government had no such intention, from the fact that a hint of this kind had appeared in the columns of one of our military contemporaries.

Dr. G. H. B. MAcheod, Regius Professor of Surgery, Glasgow University, has been presented by the senior students of medicine with several handsome pieces of plate, in recognition of his services in conducting for their special instruction a class of Clinical Surgery during the past session.

We regret to learn of the death of Dr. Andrew Wynter, at his residence, Chestnut Lodge, Grove Park, Chiswick.
Wr are informed that a committee of the Sheffield Town Council has been deputed to visit hospitals for infectious diseases situated in different parts of the country, with a view to obtain information as to the best form of construction and management to be adopted with reference to the establishment of a similar institution in Sheffield, the want of which has recently been so severely felt.

Sir JosePh FAYrer, K.C.S.I., M.D., has been appointed an Honorary Physician to H.R.H. the Prince of Wales.

Surgeon-Major H. J. Bianc has been appointed Professor of Surgery in the Grant Medical College, Calcutta.

\section{"THE BALHAM MYSTERY."}

WE have received the following important communications from Dr. George Johnson, Dr. J. F. Payne, and Dr. Redwood.

\section{MEDICAL HISTORY OF THE CASE.}

BY GEORGE JOHNSON, M.D., F R S.,

PROFBSSOR OF CLINICAT MEDICINE AND SENIOR PHYSICIAN TO KING'S COLLEGA HOSPITAX.

At half-past one in the morning of Wednesday, April 19th, I was called by my colleague, Mr. Royes Bell, to go with him to Balham to see his cousin, Mr. Charles Delauney Turner Bravo, a barrister, aged thirty, who had been suddenly seized with an alarming illness. We reached the patient's house at $2.30 \mathrm{~A} . \mathrm{M}$, and there we met Dr. Moore and Mr. Harrison, who had been in attendance since about 1030 on Tuesday night. These gentlemen informed us that Mr. Bravo was, with the exception of a slight neuralgia, in his usual good health when be sat down to dinner at about 7 o'clock. At about 9.30 he went up to his bedroom, and was soon heard to call out for warm water. A lady of the household, Mrs. Cox, found him vomiting out of the window, and apparently very ill. Dr. Moore and Mr. Harrison were sent for, and when they arrived, in quick succession, about an hour after the seizure, they found the patient partly undressed, completely unconscious, breathing heavily, with dilated pupils, cold skin, and nearly pulseless. Death appeared to be imminent. He was immediately placed on the bed, and, as he could not swallow, brandy was injected into the rectum, and a mustard poultice was placed over the heart; after a short time the heart's action began to improve, but the state of unconsciousness continued. Inquiries were made of those present, but no explanation of the alarming symptoms was obtained.

When Mr. Bell and I entered the patient's room be was still unconscious, lying on his back, breathing rather deeply; the pulse was about 100, rather feeble; the sounds and action of the heart were normal; and the pupils were then of natural size. The aspect of the patient was like that of one in the state of drowsiness following an epileptic fit. He had once vomited some blood-tinged fluid after being placed in bed, and a motion had been passed unconsciously in bed. Within about a quarter of an hour after our arrival there were signs of returning consciousness; he began to toss about uneasily, and he soon recognised Mr. Bell and replied to his questions. He now romited some mucus deeply tinged with blood; then he made violent efforts to get out of bed, complained of severe pain in the abdomen, and called for the close-stool; with assistance be got on it, and then, with violent straining efforts, he passed from the bowel a considerable quantity of blood.

About this time, soon after three o'clock, Mr. Bell called me out of the room to hear Mrs. Cox repeat a statement which she had just made to him to the effect that when Mr. Bravo was first taken ill in his bedroom he said to her, "I have taken some of that poison, but don't tell Florence" (his wife). Mrs. Bravo had been ill, and was occupying a separate room. I of course inquired whether 
he had mentioned the nature of the poison, or why or when the had taken it, to which negative answers were given. She could tell us nothing more than was contained in the above brief statement, and Dr. Moore and Mr. Harrison subsequently informed us that even this amount of information had not been communicated to them during their four hours' anxious attendance upon the apparently dying man. Mr. Bell and I then returned to the patient, who was perfectly conscinus, and I told him what we had just heard from Mrs. Cox. He said be did not remember having spoken of poison, and the only poison he had taken was some laudanum, which he had rubbed on his gums, and some of which he might have swallowed. I asked him if there were any poisons ' in the house. He said "Yes, several." I asked him to name them, and he mentioned laudanum, chloroform, and a "rat-poison" which was kept in the stable. We found in the bedroom a bottle containing laudanum, but no remains of other poison nor any vessel out of which paison bad apparently been taken. But it was quite evident that the symptoms were the result of some powertully irritant poison; there was violent pain in the abdomen, excessive tenderness on pressure, severe tenesmus, frequent passing of blood by stool, and occasional vemiting of blood. The tongue, mouth, and throat presented no appearance of abrasion. It was suggested by one of the ladies that the symptoms might be caused by Mr. Bravo's horse having run away with him during his afternoon ride; bat there had been no fall or physical injury, and it was clear that the symptoms could not be thus explained. We agreed to give cold milk as copiously as it could be taken, to foment the abdomen, and give half a grain of morphia in a suppository as often as it might be necessary to subdue the pain.

I. left him at 5.30 A.M., and took with me some of the vomited matters, which $I$ at once got tested for arsenic, with a negative result. Mr. Bell remained with the patient throughout.

At 3 P M. the same day I saw him again with the three gentlemen above-mentioned. The vomiting and purging continued, the discharges from the bowels being always bloody; there was thirst, severe abdominal pain and tenderness, the pulse was rapid and feeble, and the skin was cold and clammy. The intellect was clear. I now took away about half a pint of a bloody discharge from the bowel, which was afterwards sent to Dr. Redwood.

On Thursday, the 20tb, at 9 A.Mr., the condition remained much the same, but the vomiting and purging had been less frequent; the stools were still of a tarry character from admixture of blood, but for some hours past the vomited matters-milk, iced champagne, \&c.-bad been free from blood. The skin was sallow, and the voice feeble. There had been no usmplaint of cramps, a symptom which appear to be very common in cases of antimonial poisonirg. In consequence of the frequent romiting, nutritive enemata had been given, but they caused so much pain that they had to be discontinued.

At 2.30 r. Mr. my colleague Mr. Henry Smith saw the patient with us; there was no material change beyond increasing feehleness.

Again, at 630 in the evening, Sir William Gnll met $\mathrm{Mr}$. Bell and me in consultation. He agreed with us that the symptoms were the result of an irritant poison, and ex pressed his conviction that the poison was arsenic. The patient was again questioned, as a dying man, with regard to his having knowingly taken poison, and he repeated the statement which be had originally made to me, that the only poison had been laudanum, for the relief of neuralgia. Sir William Gull said, "You have taken poison, but it is "something more:than laudanum;" and I said, "If you die without telling us more than we know at present, some one may be accused or suspected of having poisoned you ;" to which be replied, "I am aware of that, but $I$. can tell you nothing more."

On that nccasion I looked out of the bedroom window, and found that the food which the patient had romited on the night of the 18th had lodged upon a lead-covered projecting window, about four feet below the bedroom window. I then direoted a servant to take up the vomited mater with a spoon and place it in aclean jar. This was done under my own ezes. I then sealed the jar; took it with me, and sent it on the following day; by the bands of Mr. Bell; to Dr. Redwood. I also took away a few ounces of the patient's urine, which was of natural colour and free from albumen. This I afterwards sent to Dr. Red wood.

I did not see the patient again, but I heard from Mr. Bell that he gradually sank and died at 5.20 A.M. on Friday, the 21st of April, and that, he retained consciousness to the last. He died in about 'fifty-six hours after the onset of the symptoms. The body was examined by Dr. Payne, in the presence of Dr. Moore, Mr. Royes Bell; Mr. Harrison, and myself, and an analysis of various substances was made by Professor Redwood. With reference to the post-mortem appearances, I may remark that I was at first surprised to find that; after the frequent romiting of blood, the mucous membrane of the stomach showed no signs of congestion after death. In connexion with this, it is to be observed that no blood appeared in the vomited matters after about the first four-and-twenty hours. I suppose that the sym. ptoms may be explained in the following manner. The antimony acted first on the stomach and upper part of the intestines as a local irritant, and excited vomiting first of the contents of the stomach, and then of blood-tinged mucus; next a portion of the poison entered the circulation, and the unconsciousness was probably the result of anæmia of the brain, partly due to the enfeobied action of the heart, and partly perhaps to contraction of the musenlar arterioles of the brain excited by the irritant action of the poisoned blood. Lastly, the poison was eliminated partly through the kidueys, as shown by its detection in the urine, but mainly through the mucous membrane of the large intes tine, causing there the intense eongestion and bæmorrhagic erosions which were found after death, and the severe abdominal pain and purging which continued during life.

\section{POST-MORTEM EXAMINATION ON THE BODY OF} MR. BRA VO.

(Died April 21st, 1876, ab 5.20a.m.; Exumination made April 22nd, at 9 a.m.) BY J. F. PAYNF, M.B., F.R C P.,

ASSISTANT-PIX $Y$ SICIAN TO ST. THOMAS' EOSPI'AL, RX + MENFR IN PATHOLOGY IV

Body of a young man, very well made and muscular, perfectly well nourished. Post-morem lividity of chest, shoulders, part of face and hands, sisso of nearly the whole of lower aspect of body and limbs. Moderate rigor mortis No notable decomposition. Frotby blood or blood-stained fluid issuing in considerable quantity from the mouth, and increased on pressure of the chest. No external wound, bruise, or other injury.-Pleuræ: Fach contained from two to three ounces of blood-stained fluid. No adbesions or inflammation. - Lungs: Both in the same enndition. Anterior parts of all the lobes pale and crepitant. Posterior half of upper lobe and greater part of lower lobe very dark red, nearly black, dense, but not quite airless, flnating on water, loaded with dark visoid fluid blood, which dripped off on section. This appeared to be solely due to hypostasis of liquid blood, there being no evidence of inflammation, or even certain evidence of congestion, during life. Bronchial tubes, with mucous. surface stained ot a bright red colour, from post-mortem transudation, and containing blood stained fluid, like that issuing from the mouth.-The trachea and larynx also contained blood-stained fluid of similar appearavee. Epiglottis, upper part of pharynx, and auces generally also stained in the same manner, and containing some similar fluid, resulling from transudation. Pericardium contained about half an ounce of blood-stained serum. Heart of moderate size; surface with a fen ecch motic spots; right ventricle distended with blood, chiefly liquid and gas, also containing a small soft clot, white on the upper surface, black beneath; right auricle and great veins containing dark frothy blood, mostly liquid; left ventricle nearly empty; walls relased; valves normal muscular substance of heart soft and pale; aor ta with spots of commencing atheroma. The blood generally was very dark, staining the vessels deeply, and more fluid than normal, with only small soft coagula - Abdominal organs No fluid, adhesions, or sign of inflammation in peritoneum. Stomach contained gas and liquid; its walls were of normal thickness; the mucous membrane soft, pale, yellowish, except at the lower part, where the liquid contents were lodged, and where the surface bad a diffuse red staining (from transudation). In the upper part, which was distended with gas, there were numerous small bobbles under the mucous membrane, apparently the result of post-mortem 